\title{
MEIO AMBIENTE: A PRÁTICA DA EDUCAÇÃO NAS ORGANIZAÇÕES DO EXÉRCITO BRASILEIRO
}

\section{ARTIGO ORIGINAL}

SOARES, Francisco Das Chagas Moraes ${ }^{1}$

BENTO, Cassio Michelon ${ }^{2}$

SOARES, Francisco Das Chagas Moraes. BENTO, Cassio Michelon. Meio Ambiente: A prática da educação nas organizações do exército brasileiro. Revista Científica Multidisciplinar Núcleo do Conhecimento. Ano 05, Ed. 08, Vol. 14, pp. 111-127. Agosto de 2020. ISSN: 2448-0959, Link de acesso: https://www.nucleodoconhecimento.com.br/meio-ambiente/educacao-nasorganizacoes

\section{RESUMO}

Este trabalho acadêmico de educação ambiental tem como tema a prática da educação ambiental para sustabilidade do meio ambiente, nas organizações militares do Exército Brasileiro. Seu objetivo geral consiste em realizar uma análise teórica e crítica na transmissão da educação ambiental não formal aos "novos" militares incorporados durante o serviço militar obrigatório. Como metodologia optou-se pela realização de uma pesquisa bibliográfica por possibilitar a consulta de leis, portarias, manuais, livros, artigos e documentos impressos que possibilitam o alcance dos objetivos delineados anteriormente. Entre os principais resultados obtidos foi evidenciado que antes da Lei no 6.938, de 31 ago 1981, que instituiu a Política Nacional do Meio Ambiente no Brasil, já existia no Exército Brasileiro uma a

1 Pós-graduado em Docência do Ensino Superior, em Educação Ambiental e Sustentabilidade, e em História e Cultura Afro-Brasileira e Indígena. Licenciado em História pela UNEMAT.

${ }^{2}$ Orientador. Mestrado em Botânica. Graduação em Bacharelado em Biologia. 
preocupação em preservar o meio ambiente quando nas atividades de instrução nas áreas de florestas. Ressalta-se ainda nessa pesquisa as dificuldades das organizações militares em transmitir os conhecimentos de educação ambiental aos novos soldados, tendo em vista não serem instituições de ensino.

Palavras-Chave: Meio Ambiente, Educação Ambiental, Serviço Militar, Exército Brasileiro.

\section{INTRODUÇÃO}

Este artigo apresenta uma reflexão teórica e crítica sobre a prática da educação ambiental "não formal" aos novos soldados recém incorporados no Exército Brasileiro durante o serviço militar obrigatório. Sendo observado que as organizações militares que incorporam esses soldados não são consideradas unidades de ensino, bem como não conter base curricular obrigatória de educação ambiental no período de formação do militar. Nessa análise apresenta uma abordagem superficial com as fontes pesquisadas, a exemplo do SIMEB (Sistema de Ensino Militar do Exército Brasileiro), da Lei oㅜ 6.938, de 31 agosto de 1981, que instituiu a Política Nacional do Meio Ambiente, da Lei n 9.795, de 27 de abril de 1999 (Política Nacional de Educação Ambiental) da Portaria $n^{\circ}$ 386, de 9 de junho de 2008 - IG (20-10) que aprova as Instruções Gerais para o Sistema de Gestão Ambiental no âmbito do Exército, das Instruções Reguladoras do Sistema de Gestão Ambiental (IR 50-20) na qual regula os Planos de Gestão Ambiental das Organizações Militares, e dos Programas Padrão de Instrução (PPI) que padronizam as instruções dos soldados.

A justificativa para a elaboração desse estudo deveu-se por perceber que a transmissão da educação ambiental "não-formal" aos jovens soldados durante o período militar obrigatório não era de forma "curricular", bem como "interdisciplinar" que aborde uma "educação ambiental" mais ampla, envolvendo os recrutas no processo socioambiental, cultural e econômico onde reside com sua comunidade. Deveu-se ainda, conforme prevê a (Política Nacional de Educação Ambiental), a importância de compreender e disseminar essa obrigatoriedade de educação 
ambiental para todos os níveis de ensino do Brasil, principalmente dentro dos quartéis do Exército como um órgão receptor de jovens cidadãos.

Nessa síntese abordagem, esta pesquisa tem como principal objetivo realizar uma análise sobre a prática da Educação Ambiental nas Organizações Militares do Exército Brasileiro, com a finalidade de obter uma reflexão quanto à transmissão da Educação Ambiental modalidade não-formal aos soldados recém incorporados (recrutas) na prestação do serviço militar obrigatório, bem como apresentar as dificuldades do Exército em abordar esse tema, em consonância com as exigências da nova Política de Educação Ambiental no país. Em virtude disso, afirma-se que o objetivo geral que conduziu a elaboração deste artigo consiste em realizar uma análise sobre a prática da Educação ambiental nas Organizações Militares do Exército Brasileiro.

Já sobre os objetivos específicos deste estudo definem-se da seguinte maneira: analisar a evolução histórica da política de educação ambiental no Brasil e Mundo; conhecer e conceituar as principais legislações do Exército que trata da Educação Ambiental; conhecer e analisar a Lei do Serviço Militar no Brasil; verificar a importância do sistema de ensino do Exército, principalmente na transmissão das disciplinas aos militares; destacar e analisar os Programas Padrão de Ensino do Exército (PPI) que tratam sobre o meio ambiente; e finalmente interpretar como ocorre a transmissão da Educação Ambiental não-formal aos jovens cidadãos incorporados nas organizações militares.

Como metodologia, escolheu-se a realização de uma pesquisa bibliográfica, citado acima, por possibilitar a consulta de Leis, Portarias, Decretos, Manuais, Revista Eletrônica, Livros, Teses, Artigos Científicos e documentos impressos que foram fundamentais para o delineamento da pesquisa. 


\section{FUNDAMENTAÇÃO TEÓRICA}

\subsection{POLÍTICA AMBIENTAL: UMA BREVE ANÁLISE NO BRASIL E NO MUNDO}

Segundo Ramos (1996) os governos de vários países do mundo foram incorporando as questões ambientais em suas agendas política e econômica, quando pressionados pela gravidade dos problemas ecológicos, e pelas manifestações civil contra a agressão ao meio ambiente e a vida.

Silveira (2015) ressalta que a necessidade de estabelecer políticas ambientais, ganharam destaque com o fim dos anos dourados do capitalismo (1950-1970), quando os maiores produtores de petróleo do mundo, organizados em cartéis (OPEP) e elevou o preço dos combustíveis fosseis, causando crise e tensões políticas em busca de novas fontes energéticas.

Assuntos ecológicos também foram colocados em pauta na agenda dos governantes dos países desenvolvidos quando o relatório do Clube de Roma de 1968 apresentou ao mundo as ameaças sobre o esgotamento dos recursos naturais, crescimento populacional e a degradação ambiental irreversível. (RAMOS, 2016)

Em 1972, na I Conferência das Nações Unidas para o meio ambiente, em Estocolmo na Suécia, os debates que envolviam economia e meio ambiente vieram a público através da declaração das Nações Unidas sobre o Meio Ambiente Humano, composto de 26 princípios com a visão futurista de melhorar e preservar o meio ambiente. (SILVEIRA, 2015)

Nessa Conferência esteve presente delegações de vários países do mundo, inclusive do Brasil, que apesar de ser contraio alguns posicionamentos da Conferência em relação à poluição ambiental e o esgotamento dos recursos naturais, tratou de ampliar os horizontes sobre as questões ambientais, criando no ano de 1973, a SEMA (Secretaria Especial do Meio Ambiente). (SILVEIRA, 2015). 
Junior (2005) reafirma que a posição do Brasil, bem como dos países de terceiro mundo que participaram da I Conferência em Estocolmo, posicionaram-se reativos aos princípios declarados nessa Conferência, haja vista perceberem que a relação entre "desenvolvimento e o meio ambiente", eram duas realidades antagônicas, pois as questões ambientes estavam sempre em segundo planos na ordem de prioridade. Ou seja, o desenvolvimento acima das questões ambientais.

No Brasil, a SEMA foi criada como órgão autônomo, e de administração direta coordenada pelo o Ministério do Interior em articulação com o Ministério do Planejamento e Coordenação Geral, na qual tinha como princípio compatibilizar a preservação ambiental com a utilização racional dos recursos naturais, buscando assessorar o Presidente da República na análise das implicações causadas pelo empreendimentos industriais (SILVEIRA, 2015).

A institucionalização internacional da Educação Ambiental deu um passo significativo na Conferência Intergovernamental de Tbilisi, no ano de 1977. Essa Conferência produziu um documento na qual são estabelecidos às finalidades, objetivos, princípios orientadores e estratégias para o desenvolvimento ambiental, servindo de referências para órgãos, pessoas e instituições preocupados pela educação ambiental em nível regional, nacional e internacional. (RAMOS, 1996).

Ramos $(1996$, p.16, 20) ressalta ainda que "grande parte dos países que tornaram parte na Conferência passaram a desenvolver seus programas de educação ambiental, procurando adequar tais recomendações as suas realidades".

Já na capital de Tbilisi "foi realizada a primeira conferência em educação Ambiental (EA), organizada pela UNESCO" na qual "ficou conhecida como ponto culminante da primeira fase do Programa Internacional de Educação Ambiental" (RAMOS, 1996, p.84).

No Brasil, seguindo os objetivos de Tbilisi, em Interdisciplinar as questões ambientais, institui a Lei nr 6.938 de 1981, que dispõe sobre a Política Nacional do Meio Ambiente, na qual promove a Educação Ambiental a todos os níveis de ensino, inclusive a 
educação da comunidade, objetivando capacitá-la para a participação ativa na defesa do meio ambiente. (BRASIL,1981).

Sobre os conceitos de desenvolvimento sustentável, Junior (2005) destaca que:

Em 1987, os conceitos de desenvolvimento sustentável ganharam projeções com o Relatório de Brundtland, na qual forneceu subsídios para a conferência das Nações Unidas sobre Meio Ambiente e Desenvolvimento Sustentável, realizada no ano de 1992 no Brasil onde reuniram grande número de Chefes de Estado na qual consolidou a incorporação da questão ambiental a temas de negociações internacionais. (JUNIOR, 2005, p.39)

O termo desenvolvimento sustentável está associado a uma nova ética ambiental que abrange dimensões econômicas, política, ecológica e educacional. E que esse conceito passou a ser relevante quando utilizados em documentos importantes relativo à crise ambiental no final dos anos 80 , e se firmou nos anos 90 com a ECO92. (RAMOS, 1996)

Segundo Ramos (1996, p.25) as discussões da Conferência do Rio/ECO/1992, "como ponto de partida a desigualdade que se agiganta no mundo atual e que traz como consequência o agravamento da pobreza, das doenças, do analfabetismo e a contínua pauperização dos recursos naturais."

Sobre a Conferência do Rio/1992, Junior (2005, p. 200) destaca que as autoridades do Brasil "necessitavam apresentar políticas públicas convincentes aos interlocutores internacionais em função do descaso em relação aos impactos ambientais e sociais na Amazônia", haja vista os projetos "Calha Norte e Nossa Natureza" terem se limitados apenas ao controle militar na zona de fronteiras e marketing político, dos quais causaram insatisfação internacional.

Já na Conferência Rio+20, na visão de vários analistas, essa Conferência foi uma grande decepção, haja vista não haver assinado nenhum tratado contento metas claras e prazos para atingi-las, nas quais nenhuma das grandes expectativas não se concretizou, a exemplo do Programa das Nações Unidas para o Meio Ambiente 
(PNUMA) por não ter sido transformada em agência da ONU, no que resultaria em mais verbas para a sua atuação. (DUARTE, 2012)

É importante destacar que diante de toda essa divulgação política em prol do meio ambiente em nível mundial, na década de 1970, o Brasil já possuía de "formal superficial" um rol de legislação em defesa de seus recursos naturais: a exemplo do Código Florestal de 1965; a Lei n 5.195, de 3 de janeiro de 1967 que dispõe sobre a proteção da fauna; e da Lei $n^{\circ} 6.225$, de 14 de julho de 1975 que ressalta os planos de proteção ao solo e de combate à erosão (BRASIL, 2010).

No entanto esse novo despertar sobre as questões ambientais impulsionados ao longo dos anos 70 e 80 , foram imprescindíveis para as atenções, e preocupações relacionados na preservação do meio ambiente na qual envolveram diversos países do mundo que "trataram de adequar" suas legislações ao novo ordenamento de exigência ambiental, encabeçado principalmente pelos países desenvolvidos. E que - Brasil mesmo não concordando "integralmente" com tais exigências da política ambiental a nível mundial, buscou atualizar suas leis referente ao tema, a exemplo da política Nacional de Recursos Hídricos em 1997, Crimes Ambientais em 1998, e que logo a pós a instituição da Política de Educação Ambiental em 1999, reforçou sua legislação com a aprovação da lei de Poluição por Óleo e do Sistema Nacional de Unidade de Conservação em 2000, e no ano de 2002 a Política Nacional de Biodiversidade.

\subsection{AS BASES DA LEGISLAÇÃO DO EXÉRCITO SOBRE EDUCAÇÃO AMBIENTAL}

Conforme declara a Constituição Federal do Brasil:

Todos têm direito ao meio ambiente ecologicamente equilibrado, bem de uso comum do povo e essencial a sadia qualidade de vida, impondo-se ao Poder Público e a coletividade o dever de defendê-lo e preservá-lo para as presentes e futuras gerações. (CF, Art 225). 
Nessa análise da CF (1988) envolvendo o poder público as questões do meio ambiente, o Livro Defesa e Meio Ambiente (2017) coloca em discussão que o debate do meio ambiente além de fazer parte da legislação brasileira, é crucial para a preservação da vida, e o país tem sido um importante ator neste campo, por conta de alguns bons exemplos, que inclusive ganharam reconhecimento internacional.

Destaca o citado livro que o Brasil sendo um país, marcado de riquezas naturais diversificadas, cabe a defesa não apenas de proteger esse patrimônio, mas ajudar na sua preservação como tarefa inerente ao trabalho das Forças Armadas (BRASIL, 2017).

Nessa análise, o Livro Defesa e Meio Ambiente, coloca em questão o papel das Forças Armadas Brasileira na preservação do meio ambiente, o qual cita que: "As Forças Armadas, além do seu papel na garantia da segurança nacional, promovem a educação ambiental, tendo como base o pensamento crítico e inovador, [...] e do equilíbrio ecológico." (BRASIL, 2017, p.9)

A consciência de manutenção e equilíbrio do meio ambiente pelo Exército, decorre desde a década de 1920, quando baixa um Decreto[3] determinando a proibição de cortes de árvores dos bosques e da serra de Gericinó-RJ, por parte da tropa militar quando instalada nos ambientes de florestas que pudesse prejudicar as nascentes dos rios. Demonstrando assim, desde um passado não tanto distante, o compromisso do Exército Brasileiro na proteção do meio ambiente e na integridade dos patrimônios públicos. Visão essa, que se mantém na atualidade quando todas suas Organizações Militares integram o Sistema de Gestão Ambiental (BRASIL, 2017).

Sobre os espaços ocupados pelos militares no meio ambiente durante as instruções e exercício das organizações militares, o Regulamento dos Serviços Gerais do Exército (RISG) destaca em seu art. 286: " [...] o tradicional zelo e a salutar convivência do militar com o meio ambiente, o controle ambiental, no âmbito da unidade [...]."

Portanto nessa análise do RISG, o controle ambiental e a convivência do militar com o meio ambiente são realizados pelas providências e normas de proteção adotadas 
pela Organização Militar, em consonância com a legislação em vigor de âmbito federal, estadual e municipal (RISG, art 287).

Já nos anos 90, com a finalidade de adotar uma legislação de acordo com as mudanças ambientais ocorridas no Brasil, o Exército Brasileiro, alinha-se com a Lei ${ }^{\circ}$ 9.795 de 1999 que institui a Política Nacional de Educação Ambiental. Nessa lei são definidos os princípios atinentes a Educação Ambiental que deverão ser seguidos em todo pais, na qual estabelece que a Educação Ambiental seja um "componente essencial e permanente da educação nacional, devendo estar presente em todos os níveis e modalidades de processo educativo, em caráter formal e não formal" (art. $2^{\circ}$, PNEA, Lei 9.795/99).

A citada lei, além de envolver entidades ligadas ao meio ambiente, entra também nesse rol de educação ambiental, "as instituições educacionais públicas e privadas do sistema de ensino, os órgãos públicos da União, dos Estados, do Distrito Federal e dos Municípios, e organizações não governamentais com atuação em educação ambiental" (art.7º, PNEA, Lei 9.795/99).

Prosseguindo na análise da PNEA, salienta que o ensino da educação ambiental na modalidade formal, deve ser incluído nos currículos das instituições de ensino público e privado, englobando a educação básica (educação infantil e ensino fundamental), ensino médio, educação superior, educação especial, educação profissional e de jovens e adultos. No entanto não deve ser implantada como disciplina específica no currículo de ensino. No aspecto não formal da Educação Ambiental, as ações e práticas educativas são voltadas à sensibilização da coletividade, sobre o incentivo do Poder Público nos níveis federal, estadual e municipal, principalmente na divulgação das questões ambientais, bem como na defesa do meio ambiente (art. $9^{\circ}, 10^{\circ}, 11^{\circ} \mathrm{e}$ 13ํ, PNEA, Lei 9.795/99).

Considerando o envolvimento do poder público nas questões ambientais, e na adequação internamente de suas normas e leis, conforme as exigências da Política de Educação Ambiental, citado acima, o Comando do Exército, conforme preconizado 
no SIPLEx[4], resolve baixar a Portaria $n^{\circ} 571$, de 6 de novembro de 2001, na qual aprova a Diretriz Estratégica de Gestão Ambiental do Exército Brasileiro. Além de outra premissa básica dessa portaria, destaca em suas normas que

as ações de prevenção, preservação, conservação e recuperação das áreas sob jurisdição do Exército Brasileiro e também aquelas que, eventualmente, possam vir a ser utilizadas pela Força Terrestre, principalmente as definidas como de interesse ecológico, exigem o estabelecimento de medidas preventivas, quando da realização de atividades e empreendimentos militares (PORTARIA n 571/2001).

Sobre a disseminação dos conhecimentos de educação ambiental no Exército, determina que seja através do Sistema de Ensino Militar (SIMEB), principalmente através de instrução e palestras destinados ao pessoal de todos os postos e graduações, com a finalidade de desenvolver nos militares uma mentalidade de comprometimento com a gestão ambiental (Port n571/2001, p.3).

Nessa análise, o Sistema de Ensino do Exército constituirá numa importante ferramenta em disseminar esses conhecimentos nas organizações militares, tendo o Departamento de Ensino e Pesquisa (DEP), hoje Departamento de Educação e Cultura do Exército (DECEX), com a responsabilidade de incluir o assunto de Educação Ambiental nos currículos escolares dos diversos estabelecimentos de ensino. No tocante as orientações sobre o meio ambiente relacionadas aos soldados, fica a cargo do Comando de Operações Terrestre (COTer) em inserir nos Programas Padrão de Instrução (PPI), a matéria de Educação Ambiental (Port nº 050-EME/2003).

Segundo Costa (2008), além das Portarias 571/2001 e da 050-EME/2003, que foram marcos da Educação Ambiental no Exército, inclui-se: o "Regulamento de Lei de Ensino do EB" que enfatiza a necessidade de conhecimento e preservação do meio ambiente; e a Portaria 570/2001 que determina que a Educação Ambiental deva ser promovida valendo-se do sistema de ensino.

Nesse estudo, vale acrescentar outras legislações mais atualizadas sobre o assunto: a Portaria no 386, do Comando do Exército, de 9 de junho de 2008, que orienta as ações da Política Militar Terrestre para o gerenciamento ambiental na atividades de 
caráter militar, a Instruções Reguladoras para o Sistema de Gestão Ambiental no Âmbito do Exército de 2011 (IR 50-20), e a Portaria n 142, do Comandante do Exército, de 13 de março de 2013.

No ano de 2016, com a finalidade de complemento as normas do Exército sobre as questões ambientais, o Departamento de Engenharia e Construção do Exército, aprova o Caderno de Orientação (CO) para a gestão do meio ambiente nas Organizações Militares. Esse caderno visa orientar o planejamento e execução da gestão ambiental nas Organizações Militares, enquadrando seus empreendimentos e atividades, ou seja, orientando as OM sobre a conservação, recuperação ambiental nas áreas de responsabilidades, principalmente na elaboração de seu plano de gestão ambiental e no diagnóstico ambiental (BRASIL, 2016).

\subsection{EDUCAÇÃO AMBIENTAL NAS ORGANIZAÇÕES MILITARES DO EXÉRCITO DURANTE O SERVIÇO MILITAR OBRIGATÓRIO}

Conforme preconiza a LSM (Lei do Serviço Militar):

O Serviço Militar consiste no exercício de atividades específicas desempenhadas nas Forças Armadas [...] e compreenderá, na mobilização, todos os encargos relacionados com a defesa nacional. (BRASIL,1964, art. 1ㅇ)

Sobre o Serviço Militar no Brasil, de acordo com a LSM/1964, o cidadão brasileiro ao completar 18 anos de idade e que passou pela fase de Seleção, após preencher os pré-requisitos como: física, cultural, psicológica e moral, poderá ser convocado e incorporado numa Organização Militar[5] da ativa para cumprir 12 (dose) meses de Serviço Militar (LSM/1964).

Sobre os 12 (doze) meses dos convocados nas OM, a Revista Verde Oliva (2013), ressalta que a Instrução Militar (IM) "é a parte do preparo militar de caráter predominantemente prático, visando à formação do líder em todos os escalões, à capacitação dos combatentes e ao adestramento das frações". Nessa análise, as atividades da Instrução Militar de forma continuada são definidas em "faseamento" na 
qual se insere a Fase de Instrução Individual, e a Fase de Adestramento, esta com objetivos mais amplos na capacitação do combatente no meio coletivo.

A Fase de Instrução Individual é subdividida em duas fases no processo de formação do militar que são a 1a Fase que engloba a (Instrução Individual Básica -IIB, Instrução Individual de Qualificação-IIQ), e a $2^{\mathrm{a}}$ Fase que determina o Adestramento Militar (SIMEB/2011).

A Instrução Individual Básica (IIB), de Qualificação-(IIQ) e Adestramento dos Militares são reguladas em Programa-Padrão de Instrução (PPI) de ensino, nos quais destinam habilitar os recrutas ao desempenho de suas atividades no âmbito do Exército Brasileiro. Esses Programas Padrão de Instrução (PPI), além de definirem os objetivos de cada matéria, ressaltam a responsabilidades dos responsáveis pela a instrução, referente à flora, à fauna e os recursos hídricos, assim como de fiscalizar o rigoroso cumprimento da legislação ambiental (SIMEB/2011).

No tocante ao preparo de seus quadros de instrutores e monitores do corpo de tropa, são conduzidos a Capacitação Técnica e Tática do Efetivo Profissional (CTTEP) durante $\mathrm{o}$ ano letivo com destaques a assuntos referentes à metodologia da Instrução Militar (CTTEP/2017).

Segundo (Costa 2008) após o término dos cursos de formação dos militares de carreira (Oficiais e Sargentos), já são habilitados a serem instrutores, atuando na formação dos soldados e de outros Sargentos e Oficiais, destacando em seus currículos a matéria de Educação Ambiental.

Nessa perspectiva de ensinar e aprender, os Atores Sociais "representam blocos de poder, que colocados em sinergia de interesse pela qualidade do meio ambiente e de vida, podem aprender e ensinar uns aos outros." Sendo assim, "é fundamental trabalhar com todos os Atores Sociais na perspectiva da ética do cuidado, desenvolvendo ação educativa, permanente, continuada e inclusiva nos diversos espaços." (JUNIOR, 2007, p.39). 
Na fase da Instrução Individual Básica (IIB) dos recrutas é regulada pelo Programa Padrão Básico (PPB), citado acima, no qual apresenta 26 (vinte e seis) matérias com objetivos específicos. Dentre as 26 (vinte e seis) matérias, o assunto sobre Educação Ambiental, encontra-se inserido em 2 (duas) matérias principais de "Higiene e Primeiros Socorros e Marchas e Estacionamentos", nos quais ressaltam para que os instrutores instruam os soldados a descreverem as medidas para o cuidado com a degradação do meio ambiente nas áreas de acampamento e bivaque (PP/IIB/2013).

No período de Qualificação, as noções de Educação Ambiental para os soldados já se encontram bem definidas, com carga horária de $2 \mathrm{~h}$, ressaltando principalmente à legislação ambiental em vigor (PP/IQ/2013).

Nessa análise, devido ao caráter transdisciplinar da educação ambiental, "não deverás ser abordado como matéria isolada, devendo constar em todas as instruções militares" (SIMEB/2011).

Já no Período de Adestramento, é a fase da Instrução Militar (IM), na qual o militar se encontra inserido dentro de sua fração para atuar em conjunto em diferentes cenários operacionais. Nesse período são definidas as instruções de Educação Ambiental com carga horária de 8h, com a finalidade de apresentar as considerações sobre a proteção do meio ambiente nas operações militares (CTTEP/2017).

Sobre esses documentos de Programa Padrão de Instrução (PPI) que regulamenta as instruções dos militares, Costa (2008, p.172) cita que implantação da EA institucionalizada no Exército através de regulamentos, normas e demais documentos da Força Terrestre, é nítido, bem como "a atenção dada à necessidade de capacitação de pessoal a fim de levar a efeito as intenções de preservação do meio ambiente, o que se traduz na adoção da educação ambiental do público interno". O mesmo autor comenta ainda que "essa institucionalização da EA no Exército foi imposta sob o mote do utilitarismo de fundo antropocêntrico que mais se assemelha [...] a Gestão Ambiental do que a Educação Ambiental propriamente dita." 
A educação institucionalizada e disciplinadora "devem servir de tal discussão e ampliar seu aspecto pedagógico, abrindo mais a participação, interatividade [...] de processo cognitivo e emocional nesses diversos contextos de aprendizagem" (JUNIOR, 2007, p.91).

Nessa perspectiva de participação e interatividade nos assuntos ambientais, o "estudo de caso" tem se mostrado uma ferramenta importante para compreender a complexidade da Educação Ambiental, na qual o ponto de partida para usar esta ferramenta tanto na modalidade de Educação "formal ou não formal" seria realizar uma análise investigativa do problema com "alunos ou grupos comunitários" (JUNIOR, 2007, p.140).

Segundo Gohn (2006, p. 28, 29) "Quando tratamos da educação não formal, a comparação com a educação formal, é quase que automática", entretanto "é necessário distinguir e demarcar as diferenças entre estes conceitos". A autora destaca que entre outros objetivos da Educação Formal "destacam-se os relativos ao ensino e aprendizagem de conteúdos historicamente sistematizados," enquanto a Educação não formal "capacita os indivíduos a se tornarem cidadãos do mundo, no mundo".

Nas organizações militares, essa modalidade de Educação ambiental Não Formal é repassada por programas ou atividades fora do sistema regular do ensino, na qual abrangem até "Campanhas Educativas" em parcerias com escolas, universidades, organizações não governamentais, empresas públicas etc (IR 50-20, art 38,39).

Entretanto, sobre as "Campanhas Educativas" dentro da instituição, visando uma interação mais consciente dos jovens militares junto a natureza, o Noticiário do Exército divulgou que:

No ano de 2011, o Exército aderiu à Agenda Ambiental na Administração (A3P), no qual iniciou ações de sensibilização e capacitação dos 200 mil militares dos quadros "efetivo e temporário", abrangendo aos 90 mil jovens alistados para o serviço militar, principalmente sobre o uso racional dos recursos, gestão adequada dos resíduos sólidos, licitações 
sustentáveis, qualidade de vida no ambiente de trabalho, bem como de revitalização de margens de rios, replantio de matas ciliares, tudo com a finalidade de contribuir com a formação de cidadãos conscientes. (NE, 2015)

\section{CONSIDERAÇÕES FINAIS}

A Educação Ambiental para a Sustentabilidade como um dos assuntos ainda em construção na sociedade do Brasil e no mundo, trouxe-nos alternativas de abordarmos esse tema nas Organizações Militares do Exercito Brasileiro, não como um "projeto futurista" mas de realizar uma "análise crítica" na inserção dessa modalidade de "educação não-formal" como instrumento de "sensibilização" aos jovens soldados durante o Serviço Militar Obrigatório.

Entre os resultados obtidos, destacou-se a evolução histórica sobre os problemas socioambientais do mundo, na qual deram base para se criar as Conferências Internacionais com argumentos em se discutir "ética ambiental com crescimento econômico". Em consequências, os debates na Conferência do Rio/ECO92 que reafirmou a "nova ordem" de Educação Ambiental para sustentabilidade do planeta, bem como os anseios e as frustrações políticas dos países "subdesenvolvidos" com as propostas da Conferência da Rio+20.

No que se refere à Educação Ambiental no Exército Brasileiro, foi importante realizar uma análise criteriosa das leis, manuais e portarias, principalmente dos Programas Padrão de Instrução (PPI), na qual ficou evidente que o Exército adaptou esse assunto aos citados Programas de Instrução, com a finalidade de serem ministrados na formação dos jovens soldados incorporados nas OM. No entanto é perceptível a "ausência" nesses programas de Instrução, uma modalidade de "Educação Ambiental Não Formal" com parâmetros de ensino interdisciplinar sobre os aspectos sociais, culturais, econômicos e ecológicas vividos pelos soldados, para que num futuro próximo, possam se tornar um cidadão "crítico e consciente" capazes de disseminar seus conhecimentos nas suas comunidades. 
Nessa breve abordagem, não pretendo encerrar as discussões sobre a Educação Ambiental não formal no Exército Brasileiro, como também não a considero conclusiva, espero apenas contribuir com os leitores e pesquisadores interessados em analisar as questões ambientais dentro das instituições militares oferecendo-Ihes mais uma fonte de pesquisa capaz de construir uma reflexão mais aprofundada e específica sobre $o$ assunto.

\section{REFERÊNCIAS}

BRASIL. Constituição (1988). Constituição Federativa do Brasil: Promulgada em 5 de outubro de 1988. Org do Texto Juarez de Oliveira 4. Ed São Paulo Saraiva, 1990.168 p. (série Legislação Brasileira)

BRASIL. Exército. Decreto oㅜ 57.654, de 20 de janeiro de 1996. Regulamenta a Lei no 4.375, de 17 de agosto de 1964. Lei do Serviço Militar. Disponível em:< http://www2.camara.leg.br/legin/fed/decret/1960-1969/decreto-57654-20-janeiro-> . Acesso em 2 set 2018

BRASIL. Exército Brasileiro. Portaria №008 COTER, de 29 de setembro de 2010. Aprova o Sistema de Instrução Militar do Exército Brasileiro (SIMEB). Disponível em:

https://pt.scribd.com/doc/21614389/simeb-edição2011-1. Acesso em 2 set 2018

BRASIL. Exército Brasileiro. Portaria ํo 01- COTER, de 21 de fevereiro de 2013. Aprova o Programa Padrão de Instrução Individual Básica (EB70-PP-11.0.11) $1^{\underline{a}}$ ed.2013. Disponível em: https://pt.slideshare.net/DaniellFX/programa-deinstruçãoindividual-basicaeb70pp11011. Acesso em 2 set 2018

BRASIL. Exército Brasileiro. Portaria № 3- COTER, de 19 de junho de 2013. Aprova o Programa Padrão de Instrução de Qualificação do Cabo e Soldado -Instrução da Lei e da Ordem e Instrução Comum (EB70-pp-11.012) 1를. ed.2013. Disponível em: https://pt.slideshare.net/DaniellFX/programa padrão-deintrução individual basica70pp 
BRASIL. Exército Brasileiro. Portaria ํo102- COTER, de 13 de novembro de 2017 de 2013. Aprova o Programa Padrão de Instrução e Capacitação Técnica e Tática do efetivo Profissional (EB 70-PP-11.0.14) 2 $2^{\mathrm{a}}$ ed.2017. Disponível em: https://bdex.eb.mil.br/jspui/bitstream/1. Acesso em 2 set 2018.

BRASIL. Exército Brasileiro. Portaria oㅡ 386 Estado-Maior do Exército, de 9 de junho de 2008.). Aprova as Instruções Gerais para o Sistema de Gestão Ambiental no âmbito do Exército. Disponível em:http://www.eb.mil.br/c/documen_liby/gt_file/. Acesso em 2 set 2018.

BRASIL. Exército Brasileiro. Portaria n 001-DEC, de 26 de setembro 2011. Aprova as Instruções Reguladoras para o Sistema de Gestão Ambiental no Âmbito do Exército (IR 50 - 20). Disponível em: http://www.dpima.eb.mil.br/images/manuais//IR .Acesso em 2 set 2018.

BRASIL. Lei no 6.938/81 Política Nacional do Meio Ambiente. Disponível em: http://www.planalto.gov.br/ccivil/LEIS. Acessoem: 30 ago 2018.

BRASIL. Lei no 9.795/99 Política Nacional de Educação Ambiental. Disponível em: <http://www.planalto.gov.br/ccivil/LEIS. Acesso em: 30 ago 2018>

BRASIL. Ministério da Defesa. Defesa \& Meio. Preparo com Sustentabilidade. Brasília, 2017. Disponível em https://www.defesa.gov.br/arquivos/estado_e_defesa/livro_verde/livro_defesa_meio_ ambiente.pdf>. Acesso em 2 set 2018.

BRASIL. Exército. Decreto no 57.654, de 20 de janeiro de 1996. Regulamenta a Lei no 4.375, de 17 de agosto de 1964. Lei do Serviço Militar. Disponível em:< http://www2.camara.leg.br/legin/fed/decret/1960-1969/decreto-57654-20-janeiro-> . Acesso em 2 set 2018. 
BRASIL. Exército Brasileiro. Sistema de Planejamento do Exército (SIPLEx) .Disponível em: < .http://www.defesanet.com.br/doutrina/noticia/Exercito-Brasileiro. Acesso em: 2 set 2018.

BRASIL. Exército Brasileiro. Portaria № 386 Estado-Maior do Exército, de 9 de junho de 2008.). Aprova as Instruções Gerais para o Sistema de Gestão Ambiental no âmbito do Exército. Disponível em:<http://www.eb.mil.br/c/documen_liby/gt_file/>. Acesso em 2 set 2018.

BRASIL. Exército Brasileiro. Portaria n 001-DEC, de 26 de setembro 2011. Aprova as Instruções Reguladoras para o Sistema de Gestão Ambiental no Âmbito do $\begin{array}{llllll}\text { Exército } & (\mathrm{IR} & 50 & - & 20) . & \text { Disponível }\end{array}$ em:<http://www.dpima.eb.mil.br/images/manuais//IR> Acesso em 2 set 2018.

BRASIL. Exército Brasileiro. Portaria n 571-Cmt EB, de 6 de novembro 2001. Aprova a Diretriz Estratégica de Gestão Ambiental do Exército Brasileiro. Disponívelem:<http://www.3icfex.eb.mil.br/phocadwnload/Legislação/Arquivo/portaria _571-2001-Cmteb-Diretriz_Estrategica_de_Gestão_Ambiental do EB.pdf>.Acesso em 2 set 2018.

BRASIL. Exército Brasileiro. Portaria n 050-EME, de 11 de julho de 2003. Aprova a Orientação para Elaboração dos Planos Básicos de Gestão Ambiental . Disponível em: <http://www.eb.mil.br/documents/10138/65337/port050.pdf/37f232271e59-4397-b364-5a0df81c6e8a?version=1.0>.Acesso em 2 set 2018 .

BRASIL. Exército Brasileiro. Caderno de Orientações Para Gestão do Meio ambiente nas Organizações Militares no âmbito do Exército Brasileiro. 1를. Ed.2016. Disponível em:<http://www.dpima.eb.mil.br/images/manuais/CO_Gestão_do_Meio_Ambiente.pd f. >Acesso em 2 set 2018.

BRASIL. Exército. Lei nr 5.756, de 3 de dezembro de 1971. Regulamento da Lei do Ensino do Exército. Disponível em:< http://www2.camara.leg.br/decreto-707955julho-1972>. Acesso em: 30 ago 2018. 
BRASIL. Exército. Lei o 4.375, de 17 de agosto de 1964. Lei do Serviço Militar. Disponível em:< http://www.planalto.gov.br/ccivil_03/leis/L4375.htm>. Acesso em: 1 set 2018

BRASIL. Legislação Brasileira Sobre o Meio Ambiente. 3ª Ed. Câmera dos Deputados, Brasília. 2010. Disponível em: http://ivroaberto.ibict.br/bitstream/1/716/5/legislacao_meio_ambiente_3ed.pdf $>$. Acesso em 2 set 2018.

COSTA. Ronaldo Gonçalves de Andrade. Educação Ambiental Institucionalizada no Exército Brasileiro (De) Limitações Epistemológicas das Práticas em Curso. Revista eletrônica do Mestrado em Educação Ambiental, ISSN 1517-1256, v.20, janeiro a junho de 2008. Universidade Federal do Rio Grande - FURG, 2008. Disponível em: <https://periodicos.furg.br/remea/article/view/3837/2288.> Acesso: em 23 maio 2018.

DUARTE. Ronaldo Goulart. O multilateralismo foi mais uma vítima na Rio+20?, por Ronaldo Goulart Duarte. Disponível em: http://www.revista.vestibular.uerj.br/artigo/artigo.php?seqartigo=22. Publicado em 16/11/12. Acesso em 30 ago 2018.

EXÉRCITO. Noticiário, 2015. Centro de Comunicação do Exército. Edição Especial do dia 22 de maio de 2015. Brasília-DF- Especial. Disponível em:<htt://www.eb.mil.br/web/informex> . Acesso: em 30 Ago 18.

GOHN. Maria da Glória. Educação Não-Formal, Participação da Sociedade Civil e Estruturas Colegiadas Nas Escolas. Revista Ensaio: Avaliação e políticas Públicas em educação. Rio de Janeiro, v. 14 n 50, 27-38 jan mar. Disponível em:<http://escoladegestores.mec.gov.br/site/8-biblioteca/pdf/30405.pdf> Acesso em: 30 ago 2018. 
JUNIOR. Luiz Antônio Ferraro (Org). ENCONTROS e Caminhos: Formação de Educadoras (es) ambientais e coletivos educadores. Brasília-DF, 2007. Volume 2. : 352p.: 15x21cm.. ISBN 85-7738-044-0

JUNIOR, Hermes de Andrade. Limites e Desafios aos Militares Brasileiros em Relação à Questão Ambiental. 2005. Dissertação (Tese de Doutorado, em Ciências na Área de Saúde Pública)- ESP-FIOCRUZ, 2005. Disponível em; $<$ https://www.arca.fiocruz.br/bitstream/icic>. Acesso 28 Ago 2018.

RAMOS. Elisabeth Christmann. Educação Ambiental: Evolução Histórica, Implicações Teóricas e Sociais. Uma Avaliação Crítica, 1996. Dissertação (Tese de Mestrado em Educação na área de Concentração de Educação e Trabalho) Universidade Federal do Paraná- Curtiba-PR, 1996. Disponível em: https://www.acervodigital.ufpr.br../D\%20-20ELISABETH\%20CRRISTMANN>. Acesso em: 29 Ago 2018.

SILVEIRA. Jéssica Garcia da. Entre o desenvolvimento econômico e os debates sobre meio ambiente: a Secretaria Especial do Meio Ambiente (SEMA) e a política estratégica de proteção ambiental no Brasil (19731981) www.snh2015.anpuh.org/.../1434403412_ARQUIVO_Texto_completo_SNH20 $15 \mathrm{Je}$

VERDE OLIVA, Revista, no 222. Exército Brasileiro, 2013. Disponível em; $<$ https://www.eb.mil.br/web/noticias/revista-e-multimidia/revista-verde-oliva>. Acesso 28 Ago 2018.

\section{APÊNDICE - REFERÊNCIAS DE NOTA DE RODAPÉ}

3. Decreto $\mathrm{nr} 14.237$, de 28 de julho de 1920 - aprovou a regulamentação do campo de instrução de Gericinó-RJ (BRASIL, 2017, p.17).

4. SIPEx - Sistema de Planejamento do Exército - constitui-se em um embasamento conceitual, decorrente de estudos, análises e avaliações, como o Exército deve ser 
empregado para cumprir sua missão no Plano o Estratégico do Exército. (http://www.defesanet.com.br/doutrina/noticia/Exercito-Brasileiro)

5. Organização Militar (OM) - Denominação genérica atribuída à unidade de tropa, repartição, estabelecimento [...] ou qualquer outra unidade administrativa, tática, ou operativa das Forças Armadas ( CO p.10)

Enviado: Dezembro, 2019.

Aprovado: Agosto, 2020. 